\title{
Sustainable tuberculosis control
}

$\mathrm{T}$ he overall goal of most international health projects is to have a sustainable impact on the health of the people in the country receiving aid. Hence, an important aspect in the design and implementation of any international health project is ensuring that the benefits of the project will continue once external funding ceases.

The World Health Organization and International Union Against Tuberculosis and Lung Disease Directly Observed Therapy Short Course (DOTS) strategy for controlling tuberculosis is recognized as one of the most cost effective health interventions (1), and reducing the burden of tuberculosis has been identified as one of the priorities for enhancing development by the Commission on Macroeconomics and Health (2). This strategy has five underlying principles: "1) government commitment to a National Tuberculosis Programme; 2) case detection through case-finding by sputum smear microscopy examination of TB suspects in general health services; 3 ) standardised short-course chemotherapy to, at least, all smear-positive TB cases under proper case management conditions; 4) regular, uninterrupted supply of all essential anti-TB drugs; 5) monitoring system for programme supervision and evaluation." (3). Application of these five principles is considered to be essential to the creation of a sustainable, effective program.

But what can be done when the conditions necessary for the application of all of the DOTS criteria are not all present? In Ecuador, because of political, economic and social instability, a long term government commitment to tuberculosis control is not ensured, and the central level of the National Tuberculosis Control program does not have the capacity nor the continuity necessary to ensure the appropriate training, monitoring, supervision and support that the provincial and local tuberculosis programs need to maintain a DOTS program. In response to these uncertainties, the Canadian Lung Association (CLA), as the executing agency for a Canadian International Development Agency (CIDA)-funded project to enhance tuberculosis control in Ecuador, has developed an alternative approach to supporting DOTS implementation in the country. It is through this approach that the CLA hopes to assist Ecuador to have a sustained tuberculosis control program.

This project is based on the principle of strengthening provincial and local tuberculosis control programs rather than the central level of the National Tuberculosis Control program. The principle project activities are training, to develop capacity of health care personnel in implementing DOTS, supporting the development of a laboratory network for smear microscopy and supporting the implementation of DOTS within the local health units (the primary care services of the Ministry of Public Health).

The project is limited to the basic components of a DOTS program. Case detection occurs through the identification of patients with respiratory symptoms among all those who present to the health units. Diagnosis is based on smear microscopy, and there are two treatment regimens, one for new patients and one for previously treated patients. All doses of treatment are directly observed, principally by health care personnel. The project emphasizes rigorous patient follow-up, and standard recording and reporting to monitor progress and to carry out program evaluation. Monitoring and supervision occurs at each level of care.

Preliminary data have demonstrated the success of this approach. All units in the project health areas are implementing the strategy according to project guidelines. Patient outcome data have demonstrated successful case management, with rates of patient cure or treatment completion in the first cohort analysis of $85 \%$ and an abandonment rate of $6 \%$. Case detection remains lower than expected rates but is improving with experience. In each of the project health districts, the local or provincial health authorities have assumed the ongoing costs of the DOTS program.

This project is funded for three years and is limited to three of the 22 provinces in Ecuador that together account for approximately $50 \%$ of the tuberculosis cases in the country. From the outset of the project, the CLA has been concerned about the necessity of ensuring sustainability of the program once the funding and technical and administrative support have ended.

How can the likelihood of sustainability be measured? In 1993 and again in 1993, the Auditor General of Canada identified four key indicators for CIDA as criteria to determine whether a project's results are likely to provide sustainable benefits after CIDA's direct funding ends (4).

- "Technical and managerial capability or readiness of the recipients (recipient country or 'inheritor' institution) to sustain the project.

- Commitment of the 'inheritor' to assume ownership and responsibility for sustaining the project. 
- Target group involvement in project design and evaluation, and the value it places on the development benefits.

- Availability of sustaining resources - cash and other resources - to operate and maintain the project over its life cycle.

From its outset, the project has identified specific responsibilities of the government of Ecuador that demonstrate the government's commitment to maintain the program. Since the project began, the government of Ecuador purchased and distributed sufficient first-line antituberculous medication and laboratory supplies for the entire country, and has taken on recurrent costs of the program in each project area. In this way, sufficient funds for these costs have been incorporated into the health care budget of the country. In addition, the government has provided the infrastructure and health care personnel for the tuberculosis program within its primary care network; for the most part, these are individuals who already have secure, full-time positions within the Ministry of Public Health.

Because of the lack of stability and continuity at the central level, the project has emphasized ownership of the project and leadership of the program at the provincial and local levels, and development of technical and managerial capacity at these levels. Tuberculosis program staff at the provincial and local levels have been trained in the basic aspects of tuberculosis control, and those at the provincial level have received additional training in computer skills. In addition, provincial staff and those identified as leaders at the local level have been strengthened as trainers themselves, and in their role in monitoring, supervision and evaluation.

Increasing capacity and involvement of the target group has occurred through the implementation strategy at the local level. While extensive support is offered to each new facility as DOTS is being implemented, each area is expected to implement the program independently and to adopt the strategy to their own local conditions. Health care personnel have recognized their abilities to solve local prob- lems, without direction from the central level. In addition, they have recognized their abilities to implement a program of international calibre. This recognition has both increased the value that the target group places on the program, and has created an institutional (ie, health area) recognition of the benefits and the importance of the program.

The project team believes that this strengthening of local capacity will mitigate the effect of the frequent political changes at the national level. In addition, through the training, meetings and workshops, the project has allowed the provincial and local staff to make stronger connections with each other, and to have a greater awareness of the responsibilities of the central level and a collective expectation that these responsibilities will be met. This strengthening may enhance the ability of provincial and local levels to insist that the central level meet its commitments.

As this phase of the project enters its final year, the focus will be on ensuring that the skills and expertise necessary to continue the program are transferred to provincial and local staff so that the remarkable advances made to date will continue to improve the treatment of tuberculosis in Ecuador.

\section{Terry-Nan Tannenbaum MD MPH Medical Advisor for International Activities, Canadian Lung Association}

\section{REFERENCES}

1. The World Bank. Investing in Health: World Development Report 1993. New York: Oxford University Press, 1993.

2. Sachs JD. Macroeconomics and Health: Investing in Health for Economic Development. Report of the Commission on Macroeconomics and Health. World Health Organization, 2001. $<$ http://www.cid.harvard.edu/cidcmh/CMHReport.pdf $>$ (Version current at December 9, 2002)

3. Treatment of Tuberculosis: Guidelines for National Programmes, Second Edition. Geneva: World Health Organization, 1997. (WHO/TB/97.220).

4. Auditor General of Canada. 1998 Report of the Auditor General of Canada, Chapter 21 - Canadian International Agency Geographic Programs, December 1998. < http://www.oag-bvg.gc.ca/ domino/reports.nsf/a1b15d892a1f761a852565c40068a492/ 4b611b936e377129852566c60052725c?OpenDocument> (Version current at December 8, 2002). 


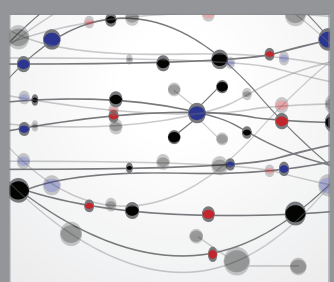

The Scientific World Journal
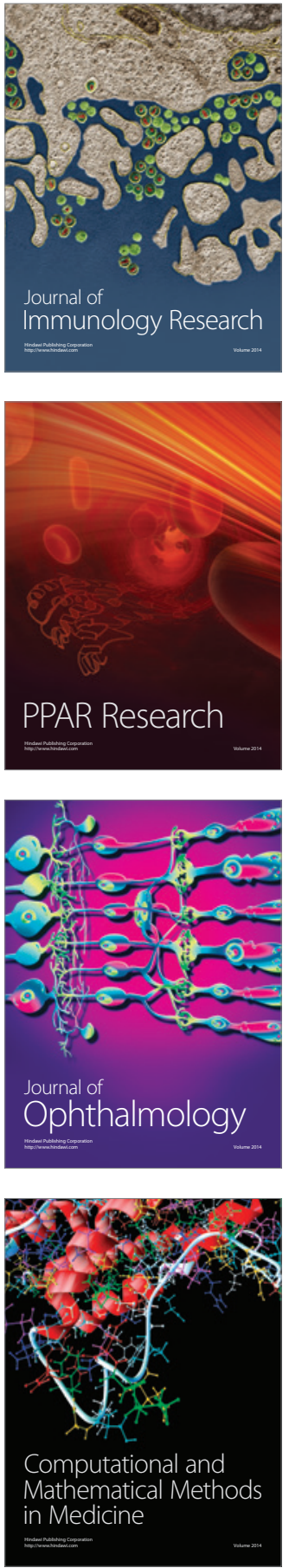

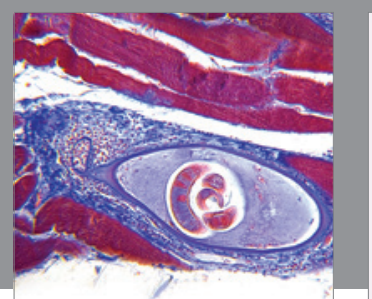

Gastroenterology Research and Practice

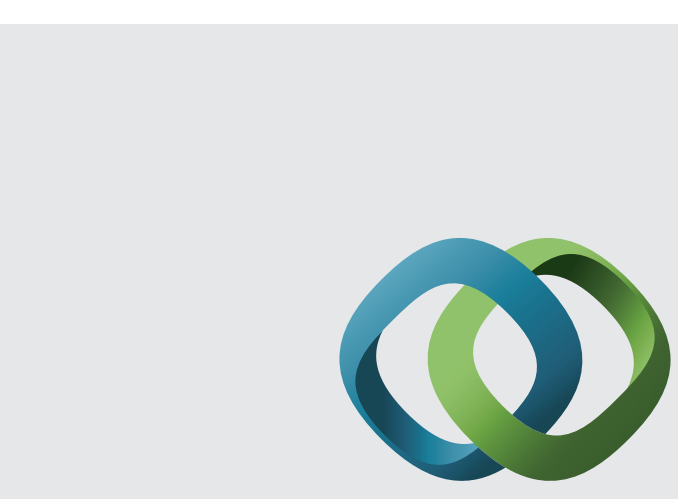

\section{Hindawi}

Submit your manuscripts at

http://www.hindawi.com
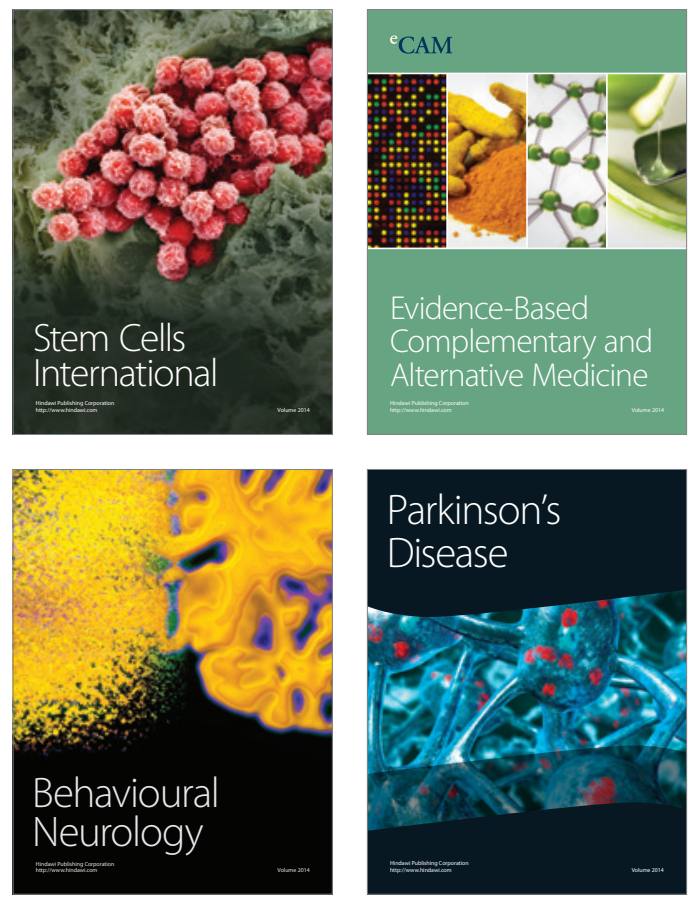
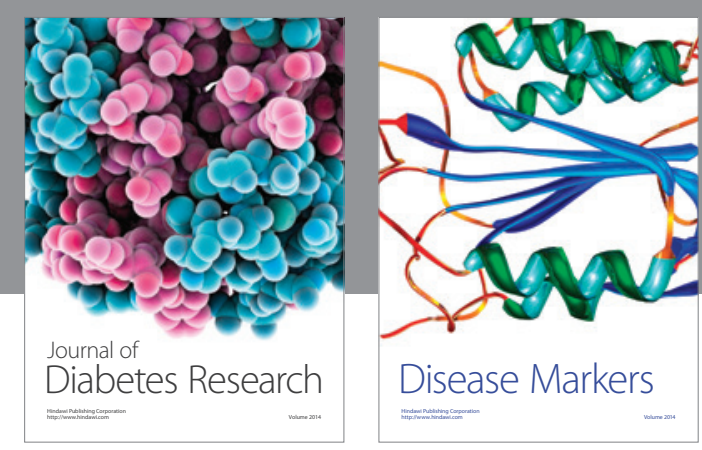

Disease Markers
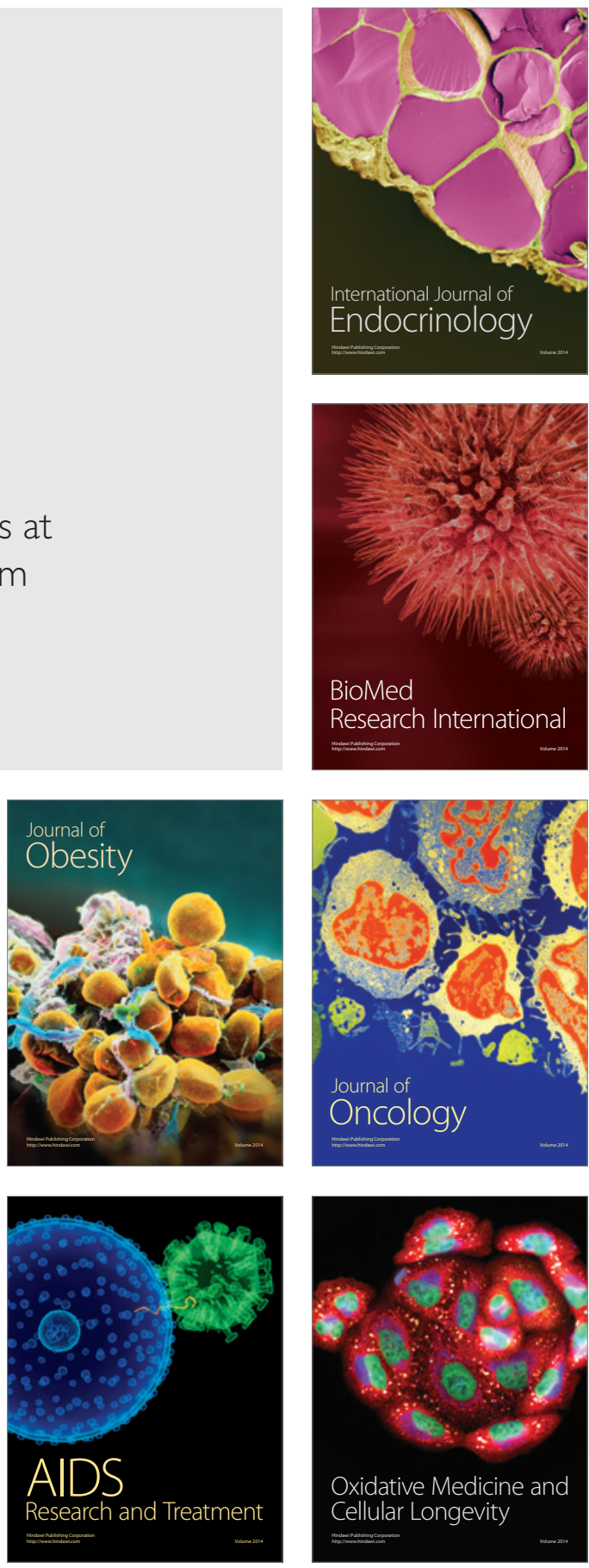